\title{
Introducing a Domain Ontology based on the Role of Trusted Third Party (TTP) in inter-Organizational Collaboration
}

\author{
Neda Zeighami \\ Department of Computer \\ Engineering \\ Science and Research Branch, \\ Islamic Azad University \\ Tehran, Iran
}

\author{
Mir Ali Seyyedi \\ Department of Computer \\ Engineering \\ Tehran Jonob Branch, Islamic \\ Azad University \\ Tehran, Iran
}

\author{
Mehran Mohsenzadeh \\ Department of Computer \\ Engineering \\ Science and Research Branch, \\ Islamic Azad University \\ Tehran, Iran
}

\begin{abstract}
Due to the need for information exchange between enterprises and different formats and standards in each organization, interoperability and flexibility between enterprises are difficult. Hence, a space needed to standardize documentation, transaction Choreographyes between international enterprises is felt. In such circumstances, this space is called Collaboration space. To create a fair, non-repudiation and secure collaboration space, trusted third party (TTP) is used to facilitate collaboration and interaction between enterprises. Instead of any of the partners interact with each other; they can communicate with a TTP. One of the new topics in the IT and business alignment is enterprise interoperability in various business domains. One of the best ways to identify business domains is business modeling and one of the key tools in the modeling business is business domain ontologies. Ontologies introduce the core concepts that exist in some domain of interest and the relationships that hold among them and they can be used in modeling of business domains.

In a collaboration space and for enterprise interoperability, each business domain according to their needs, uses the specific ontology to create models of their business. In the field of business domains there are three ontologies to model business. Our focus in this research has been the development of the REA ontology.

The project aims to provide ontology for modeling collaboration space concepts based on a TTP in the interoperability of enterprises. To collaboration space between enterprises has established, the public processes, border collaboration and the main concepts of the domain ontology associated with the related ontology must be identified. The collaboration space between enterprises is a heterogeneous space in terms of technology and in terms of ontology. Also in this space some issues are important such as authentication of partners in domain, guarantee of limited access control of partners to resources, non-repudiation of partners, recovery of lost information and translation of different domains. These characteristics are achieved through trusted third parties. In order to implement a TTP, a domain-specific ontology to describe the collaboration space is needed.
\end{abstract}

\section{General Terms}

Business domain ontology covering TTP

\section{Keywords}

Ontology, Interoperability, Business Domain, Business Domain Ontologies, Trusted third party (TTP), REA.

\section{INTRODUCTION}

As regards, nowadays enterprises to respond to their needs, must interact and collaborate with other enterprises and because of each organization has its own standards, formats and documents, the need for a collaboration space between the enterprises is felt. This collaboration space focus on internal organization process rather than focusing on public processes. When two business partners interoperate together, they must have a collaboration space to share information and exchange documents to reach economic values. So the collaboration space between business partners is formed when they interoperate together so they can respond to their needs. The collaboration space is composed of a number of transactions. The tasks of these transactions are to exchange messages, documents and information. In fact, collaboration space, in addition to standardize documentation and does transaction Choreographyes. From the perspective of each business partner the collaboration space is different. For the interaction between two or more partners, collaboration agreement must be defined .Usually; partners will interact through an agreed profile. Each profile agreed identified border collaboration from a different perspective. Based on this profile, partners realize the collaboration process. In this case, the interaction between the partners can be ensured. Business partners interact together in the collaboration space. This means that they do activities that include resources interaction to obtain the value.

Interoperability is a feature that implies the ability to work on multiple systems and organizations to work together. The term interoperability has many definitions; a reasonable one is:

The ability of a collection of communicating entities to (a) share specified information and (b) operate on that information according to a shared operational semantics [1].

To create a common understanding of the concepts and relationships between them in a certain domain, ontology is used [1].

Philosophers have studied ontologies for centuries in their search for a systematic explanation of existence: "What kinds of things exist?" Recently, ontologies have emerged as a major research topic in the fields of artificial intelligence and knowledge management where they address the content issue: "What kind of things should be represent?" The answer to that question differs with the scope of the ontology [2].

Ontologies that are subject-independent are called upper-level ontologies, and they attempt to define concepts that are shared by all domains, such as time and space. Domain ontologies, on the other hand, attempt to define the things that are relevant to a specific application domain. Both types of ontologies are becoming increasingly important in the era of the internet where consistent and machine-readable semantic definitions of economic phenomena become the language of e-commerce [2].

This is a question of ontology: a formal specification of the concepts that exist in some domain of interest and the relationships that hold among them [5]. 
Domain ontology tries to define objects related to a specific application. Domain ontology is using for recognizing concepts in a collaboration space.

In the domain ontology, the identification of the key concepts that exist in collaboration space between enterprises is followed. The key concepts (axial) are:

Partners, documentation, messaging, transactions and public processes.

This project describes REA Ontology of MacCarthy model as domain ontology. REA is focused on increasing and decreasing resources.

MacCarthy presented REA ontology based on the accounting principles theories and believed that any event that increases business resources is associated with other events that reduces business resources [3]. For this ontology, UMM methodology is presented [4].

One of the key concepts in this space is a TTP. It is used to create a safe, secure, reliable collaboration space. Also it authenticates the partners, guarantees of access control to resources, non-repudiations of partners, recoveries of lost information and translates different domains of partners in collaboration space .Therefore, it is necessary to have a space with mentioned characteristics by each of the partners, which is achieved by using a TTP. In order to model the collaboration space that covers a TTP, the need for business domain ontology based on the trusted third party is essential. Unfortunately, none of the proposed ontology does not provide reliable TTP. Only ontology OeBTO in its mediated transactions uses TTP. However a secure, fairness and nonrepudiation collaboration space cannot be used. OeBTO ontology is a formal, rule-based specification and definition of the concepts pertaining to business transactions and scenarios of Open-edi and the relationships that hold among those concepts with REA ontology [5]. Therefore, this research has tried covering the REA ontology with TTP for collaboration space modeling with features of security, fairness, and nonrepudiation. Hence, this project will expand REA ontology that included concepts in the domain of business and the relationship between them. New proposed ontology models collaboration space covering TTP.

Section two motivates REA ontology as object of study. Extended REA is also demonstrating as business modeling ontologies. In Section three there is the evaluation. The case study of improved REA is developed in the fourth section. Section five ends with conclusions and future work.

\section{Extended REA}

The proposed method presents a domain ontology covering TTP. For this purpose, concepts in economic business domain are used and REA ontology related between this concepts. Thus, the resulting ontology is developed REA ontology. The ontology exploit from TTP. This developed ontology model the concepts of collaboration space based on TTP. Thus includes services that TTP is offering in the exchange. The ontology also takes over a variety of TTP. A TTP can have different roles to play in the REA ontology, which provides a variety of services. All of services and roles are described in the extended REA ontology.

Using the developed REA ontology, fairness and secure collaboration space can be modeled with a TTP. Also in this space some issues such as authentication of partners, guarantee of access control to resources, recovery of lost information and translation of different domains are assured. Following sections examine the components of the new REA ontology.

This research presents the development of a new REAontology that uses an OWL UML profile for graphically representing ontologies (OMG 2006). This specification of the ontology in single representation formalism is more complete than previous representations, should still be easy to understand by business professionals and can also be easily transformed into a machine-readable representation [6].

\subsection{TTP Contract}

As ontology REA, set of commitments to be defined in a contract. To define TTP in REA Ontology; first, a contract must be signed between the partners and a TTP. An Economic commitment is a promise to execute an Economic Event at some point in the future [5]. Each commitment reserves resource, fulfills events and involves agents. Thus, a contract between the TTP and partners must be related with the resources, events and partners.

Contract between the partners and TTP, is a subclass of general contract in REA ontology. Figure 1 shows the contract between the partners and a TTP and the relations between them.

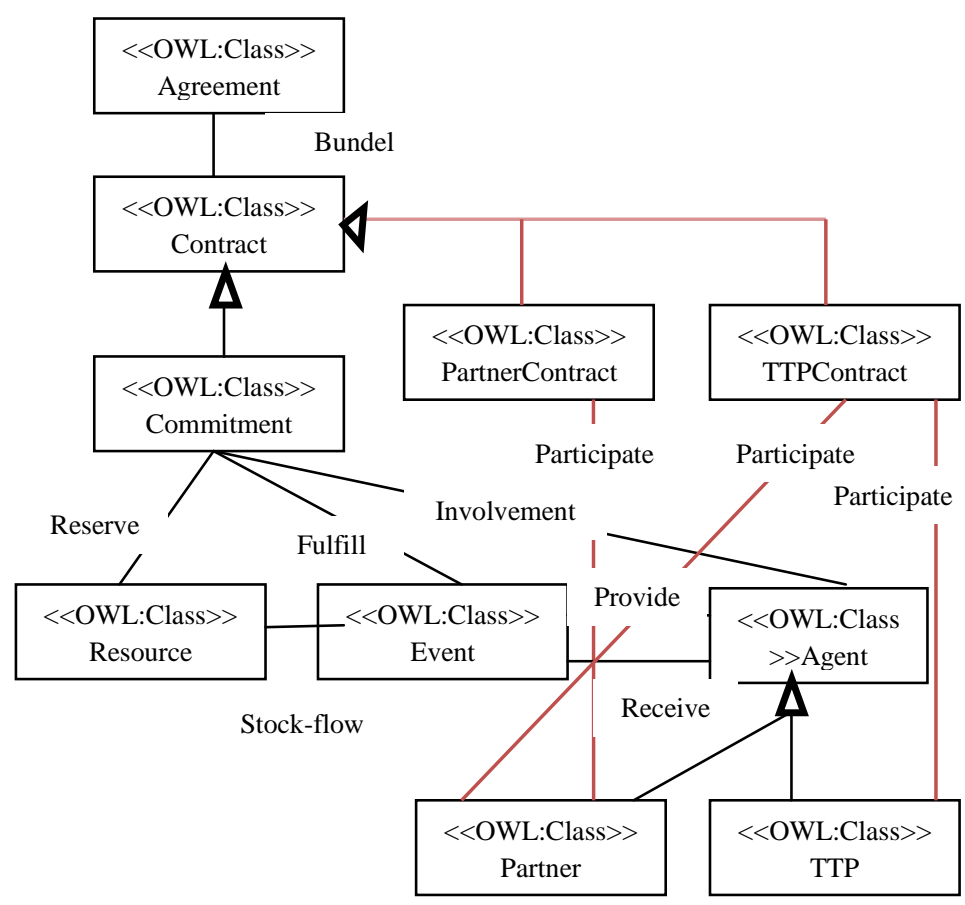

Figure1: Collaboration space with TTP contract in REA

\subsection{Collaboration model}

According to the signed contract, TTP that participates in the collaboration space between the partners, have three different types: inline, online and offline [7,8].

The following, types of TTP will be explained.

\subsubsection{Offline trusted third party}

Offline TTP does not participate in the exchange between partners directly but in every exchange between partners, evidence is sent to the TTP. If there is a dispute, TTP can collect evidence from disputing parties and then to make a decision which will resolve the dispute with recovering information [8].

\subsubsection{Inline trusted third party}

Inline TTP participates directly in the interaction between partners. Each of the partners rather than sharing with other partner, communicate to a TTP. 


\subsubsection{Online trusted third party}

Online TTP only participates in the initial exchange between the partners directly. Subsequent exchanges between partners are done without TTP. Figure 2 models different collaboration of a TTP can provide.

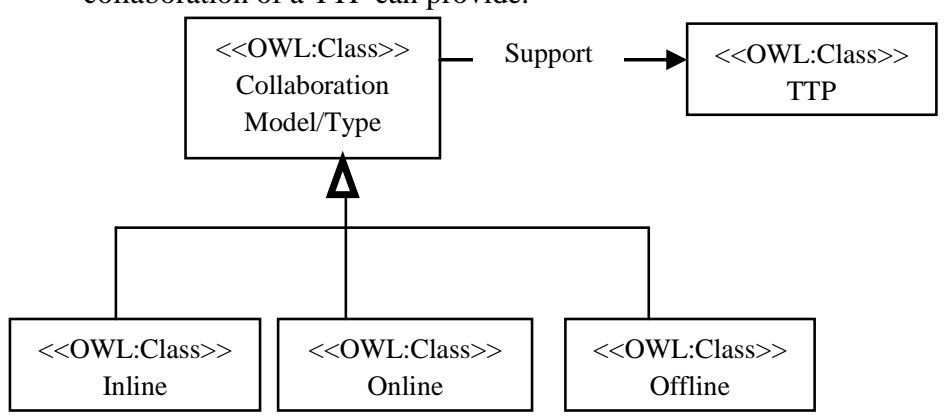

Figure2: Collaboration models of TTP

\subsection{Extension of the REA into Types}

Abstract concepts are information structures used to describe the intangible components of actual phenomena [5].

For ontologies, this is an important distinction. In the OeBTO ontology, "type images" are used to represent the abstract structure of economic phenomena [5].

In REA Ontology, agents can be divided into two sub-classes of "partner" and "Trusted third party". Thus, based on the REA ontology, two separate typification can be defined: "person role" and " trusted third party role ". In the UML class diagram of Figure 3, person and TTP are typified to produce their abstract specification classes shown at the top of the figure (Person Role, TTP Role). Figure 3 illustrates resource and resource types, event and event types, agent and its subclass and economic roles in the REA ontology. desires goods or services) and the other assuming the role of a "seller" (has goods or services, desires money) [5]. The buyer begins the transfer of acceptable equivalent value, usually in money, to the seller providing the good, service and right [1518]

Figure 4 demonstrates the role of the partner and its subclasses.

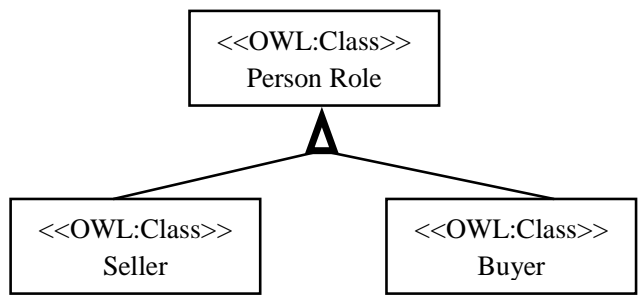

Figure4: Person role and its sub-classes

\subsubsection{TTP Role}

A TTP can play the roles of mediator, guarantor, escrow, notary and translator.

Figure 5 demonstrations the role of the TTP and its subclasses.

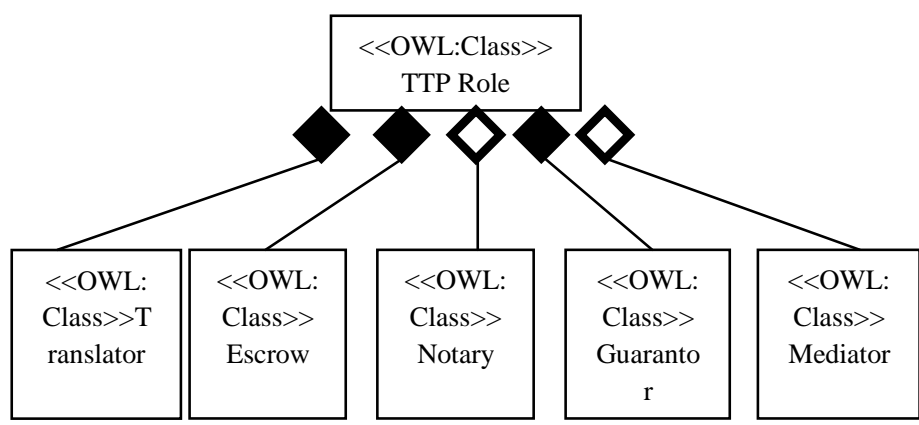

Figure5: TTP role and its sub-classes

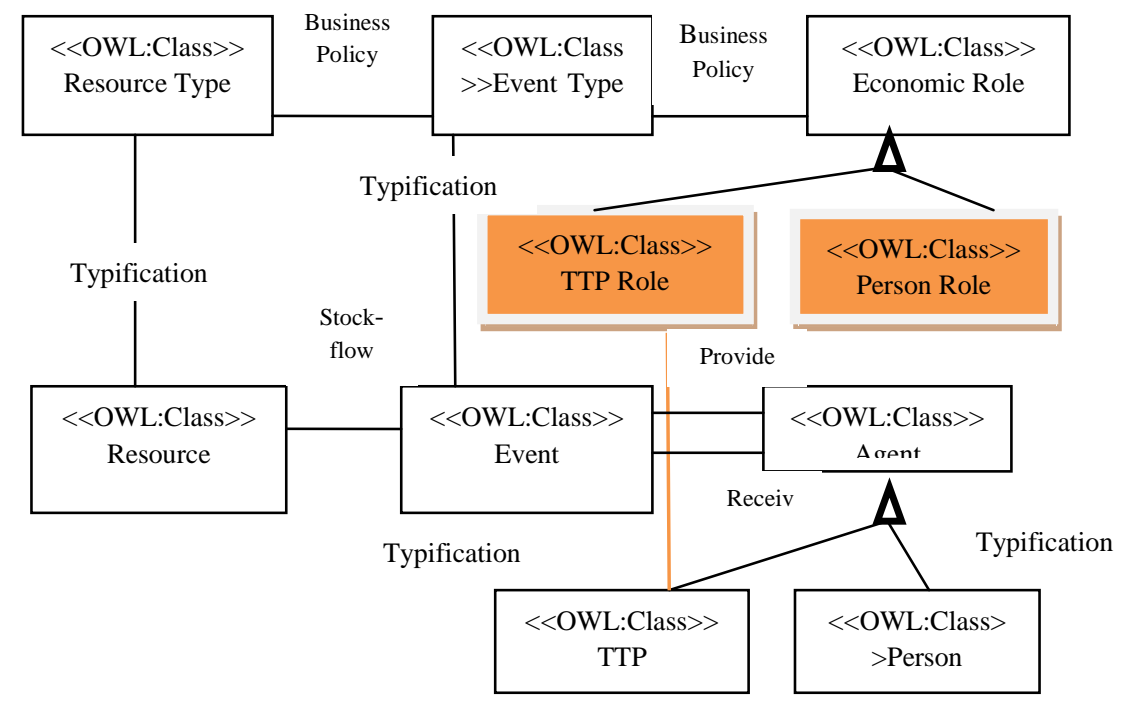

Figure3: Economic roles in REA

\subsection{1-person role}

Each partner will play a different role in the exchange [9]. Since proposed research used the REA ontology and the ontology are related to economic and accounting area. Here, exchange means, buying and selling between partners [9-14].

Most generally, there is a value exchange between two persons, with one assuming the role of a "buyer" (has money,
In the above figure, the hollow diamond indicates that TTP should play mediator and notary roles. According to types of collaboration models of TTP, it can have several roles as it is illustrated in figure 5 . 


\section{Evaluation}

In the proposed method, a new ontology covering a TTP is used. However, the quality of the domain ontologies in the field of accounting and economic based on metrics of [18], can be assessed. Table 1 compares the assessment quality of REA ontology covering a trusted third party with the REA ontology.

Table1- Comparison of two ontology based on metrics and related questions

\begin{tabular}{|c|c|c|c|}
\hline Goals & Questions & REA & $\begin{array}{l}\text { REA } \\
\text { Covering } \\
\text { TTP }\end{array}$ \\
\hline \multirow[t]{3}{*}{ Completeness } & $\begin{array}{l}\text { Are all Concepts in the } \\
\text { domain ontology are } \\
\text { covered? }\end{array}$ & $x$ & $\checkmark$ \\
\hline & $\begin{array}{l}\text { Are all the available } \\
\text { evidence registered with } \\
\text { the concepts in the } \\
\text { ontology? }\end{array}$ & $x$ & $\sqrt{ }$ \\
\hline & $\begin{array}{l}\text { Are all the concepts } \\
\text { recoverable? }\end{array}$ & $x$ & $\checkmark$ \\
\hline \multirow[t]{3}{*}{ Preciseness } & $\begin{array}{l}\text { Are the following } \\
\text { principles and axioms of } \\
\text { sub-classes correct? }\end{array}$ & $\checkmark$ & $\checkmark$ \\
\hline & $\begin{array}{l}\text { Is there (is-a) relations } \\
\text { in the ontology? }\end{array}$ & $x$ & $\checkmark$ \\
\hline & $\begin{array}{l}\text { Are the objects scope } \\
\text { are properly defined and } \\
\text { guaranteed? }\end{array}$ & $x$ & $\checkmark$ \\
\hline Clarity & $\begin{array}{l}\text { Is the terminology } \\
\text { consistent in the } \\
\text { ontology? }\end{array}$ & $\checkmark$ & $\checkmark$ \\
\hline
\end{tabular}

\section{Case study}

For case study, Mizaan scenario is considered. In this scenario, in order to increase the purchasing power of workers and government employees, Mizaan credit card will be distributed among the claimants. It also sets up new purchase network and the amount of purchase is deducted from the salary of employee.

The first phase of the project, the staff members of the organization, can buy a variety of merchandise and services with consuming specified credit from the stores and shopping centers which have contracts in the Mizaan network (inquiries based on the Organization's salary and other parameters) and the organization will be deducted the credit amount from the employee's salary.

In the scenario of deducting salary and consuming credit, there are two business partner and a TTP and within each of area of them there are terms should be clarified: According to the case study, concepts in REA are:

\section{* Contract}

- Issues Credit Card for employees with guarantee of her/his organization.

* Commitment

- Bank: amount purchase payment Obligation according to the specified credit.

- Organization: Debt payment Obligation of employee to credit issuing bank.

- Event

- Bank: Reduced from the credit and debit declaration.

- Organization: deposit liabilities to credit Issuing bank

* Resources

- Bank: credit

- Organization: Profit Account

* Agents

- Organization: guarantees of debt fee that reduced from the employee's salary will be announced by the Bank

- Bank: issues the card with guarantees of organization for employee

* TTP

- Governs the interaction space

Employees can buy from shopping centers and consume their specified credit. Amount deducted from the credit employees by the Bank (Decrement) and be transferred to the sellers account thus the bank provide credit card according to its commitment and expect from organization to return the payment with reduces from employees salary.

\section{Conclusion and future work}

To make safe, reliable, non-repudiation collaboration space and to identify partners in the domains, guarantee of access control to resources, recovery of lost information and translate of different domains of partners, an additional agent is used in ontology .The trusted third party is the agent who will participate in the exchange between the partneDue to the growing ontology and its implications in various domains, new concepts and new functionality can be used in the ontology.In order to provide an efficient Ontology,new concepts can be added to the ontology.The TTP in the ontology covering technique was evaluated in terms of reliability.In this document, ontology covering TTP was evaluated from the technical aspect. However, the concepts in a trusted third party can be implemented.The focus of this project, is adding a TTP to REA ontology. A TTP can add to other businesses domain ontologies such as BMO and e3 value.

\section{REFERENCES}

[1] D. Carney, D. Fisher and P. Place: "Topics in Interoperability: System of Systems Evolution, ' Software Engineering Institute, Carnegie Mellon University, March 2005.

[2]Guido L. Geert and William E. McCarthy "The Ontological Foundation of REA Enterprise Information Systems", November 1999, March 2000, August 2000.

[3] McCarthy, W.E. "The REA Accounting Model: A Generalized Framework for Accounting Systems in A Shared Data Environment." The Accounting Review (July), pp. 554-578. 1982.

[4] UN/CEFACT Modeling Methodology: User Guide, http://www.unece.org/cefact/umm/ UMM_userguide_220606.pdf.

[5]ISO/IEC 15944-4 INTERNATIONAL STANDARD:' Information technology - Business Operational View - 
Part 4: Business transaction scenarios-Accounting and economic ontology , 2007.

[6] Frederik Gailly ,Geert Poels,"Ontology-driven Business Modeling: Improving the Conceptual Representation of the REA Ontology", February 2007

[7] EG 201057 V1.1.2 (1997-07) ETSI Guide: "Telecommunications Security; Trusted Third Parties (TTP); Requirements for TTP services", European Telecommunications Standards Institute, 1997.

[8] Draft EN 301 099-1 V1.1.1:"European Standard (Telecommunications series) Telecommunications Security; Trusted Third Parties (TTP); Specification for TTP services; Part 1: Key management and key escrow/recovery", (1997)

[9] ISO/IEC 13888-1: "Information technology - Security techniques - Non-repudiation!Part 1: General Model", 1997.

[10] ISO/IEC 13888-2: "Information technology - Security techniques - Non-repudiation؛ Part 2: Using Symmetric Techniques", 1998.

[11] ISO/IEC 13888-3: "Information technology - Security techniques - Non-repudiation؛ Part 3: Using Asymmetric Techniques", 1997.
[12] ISO/IEC 10181-4: "Information technology - Security frameworks in open systems: Non-repudiation framework ", ITU-T Recommendation X.810 (1995).

[13] Howard P and Mitchell C: "Requirements for Trusted Third Parties", Aspect Project, ACTS, Programmed, 29 May 1996.

[14] Guido L. Geert and William E. McCarthy "The Ontological Foundation of REA Enterprise Information Systems", November 1999, March 2000, August 2000.

[15] ISO/IEC 15944-1: INTERNATIONAL STANDARD:' Information technology - Business Operational View Operational aspects of Open-edi for implementation",2006

[16] ISO/IEC 15944-4 INTERNATIONAL STANDARD:" Information technology - Business Operational View Part 4: Business transaction scenarios-Accounting and economic ontology, 2007.

[17] ISO/IEC 14662:” Information technology — Open-edi reference model", 2004.

[18] Lina TANKELEVI “ CIEN`E,Robertas DAMAŠEVI CIUS."Chara cteristics of Domain Ontologies for Web Based Learning and their Application for Quality Evaluation”, 2009 